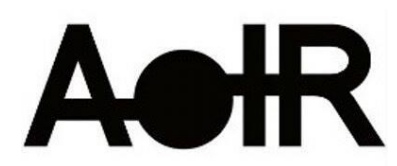

Selected Papers of \#AoIR2020:

The $21^{\text {st }}$ Annual Conference of the

Association of Internet Researchers

Virtual Event / 27-31 October 2020

\title{
TEMPORAL FRAMES FOR PLATFORM PUBLICS: THE PLATFORMIZATION OF BREADTUBE
}

\author{
Aikaterini Mniestri \\ Siegen University, Germany \\ Alex Gekker
University of Amsterdam, Netherlands.
}

In this paper we suggest the notion of platform publics to account for the intermingling of socio-technical processes that make online platforms (in this case: YouTube) resistant to stable definitions. It has been over a decade of YouTube studies and yet, a consensus on what precisely YouTube is seems unlikely. Arguably, Burgess and Green began this ontological quest with the first edition of YouTube (2008) in which they set out "to work through some of the often-competing ideas about just what YouTube is." (iv) Snickars and Vondereau (2009) considered the "ontological ambivalence" (2009, p. 28) of YouTube to be an asset since the platform's success was rooted in its flexibility as a stage for content. Following work attempted to understand YT as a 'new screen ecology' (Cunningham 2016); through its platform logics of monetization and viewership (Postigo 2015, Van Es 2020); as a contested space between creators, content and audience (Berryman and Kavka 2018, Bishop 2018; 2019); and as a database, often implementing scraping and other computational techniques to account for its nature as vast graph network of content (Airoldi et al. 2016) with internal algorithmic dynamic - for instance the preference of "YT-native" content over mainstream actors within its search and recommendations (Rieder et al. 2018). However, this methodology, too, confronted the researchers with "the realities of an intricate mesh of mutually constitutive agencies that frustrate our desire for causal explanation" (ibid 65). Addressing all the above, our call is thus to abandon the ontological stability of YT as a singular object and instead present it from a post-representational (Thrift 2008) and temporally-orientated (Adam 2008) perspective. Using a case study on the emergence, convergence and schism of left-leaning content creators and publics - known as BreadTube - on the platform, we refrain from asking what $\mathrm{YT}$ is, but rather where and when $\mathrm{YT}$ happens.

From the election of Donald Trump and through a series of escalating events radical right wing ideologies penetrated the vernacular of politicians and other public figures.

Suggested Citation (APA): Mniestri, A., Gekker, A. (2020, October) Temporal Frames for Platform Publics: The Platformization of Breadtube. Paper presented at AolR 2020: The 21th Annual Conference of the Association of Internet Researchers. Virtual Event: AolR. Retrieved from http://spir.aoir.org. 
(Norman 2020, Tuters 2020). At this moment in time, YT rose to infamy as an alt-right pipeline, arguable 'radicalizing' users towards reactionary content (Tufecki 2018, Lewis 2019). In response, numerous creators began to produce videos on the platform whose purpose was to provide counterpoints to the discursive narratives of the alt-right around the issues of anti-feminism and racism. What had begun as an incidental trickling of politically left-leaning channels consolidated, by 2018 , into a strong community of interlinked channels. A running point for mass recognition was a prominent exposé in the Verger, where Natalie Wynn (of the "ContraPoints" channel) was hailed as the "Oscar Wilde of YouTube" (Cross 2018). Soon, the so-called "BreadTube" (or LeftTube) amassed a substantial following on YT but - importantly - also on other platforms, like Reddit and Twitch.

In other words, controversies around reactionary rhetoric fertilized "discrete and identifiable sites of uncertainty and creativity" (Burgess and Metamoros Fernandez 2016, p. 81-82) rendering BreadTube an "issue public." (81) This is, for the most part, the image that Kuznetsov and Ismangil (2020) have captured, painting BreadTube as a "catalyst, an agent preparing and hastening up conditions for change." (205) and denoting it as a "socialist movement." (216) As we show, taking a snapshot of BreadTube at precisely the right moment might produce such an image, but it can be misleading without taking into account the temporal dynamics of the platform and the issue publics converging on it. Case in point is the release of "Opulence," video in October 2019 which caused a severe rift in the community. To us, this again challenges the presumption that one can capture a single static image of $\mathrm{YT}$, or any public that exists on it. With that in mind, this paper examines BreadTube not as a successful or failed movement, but as an apt case, which reveals the complexity that a temporallyoriented perspective can bring to the study of platform publics.

This is all the more important in the face of platformization (Helmond 2015). YT has followed Alphabet's trajectory in replacing a two-sided market with a much more complex multi-sided market (Rieder and Sire 2014), where advertisers, content creators and audiences are all pitted against each other for YT's sake. Within this multi-sided market, cultural production is articulated through the affordance of particular types of "activities, connections, and knowledge" (Nieborg and Poell 2018; 6). Thus, BreadTube should be seen as a momentary crystallization of an issue public, positioned as much within the creator anxiety surrounding the production and streaming of video content 
online and its (cross-)platformization (Bishop 2018;2019) as it is within a certain political discourse.

\section{References}

Adam, Barbara. "Of timescapes, futurescapes and timeprints." Lüneburg University 17 (2008).

Berryman, Rachel, and Misha Kavka. "Crying on YouTube: Vlogs, self-exposure and the productivity of negative affect." Convergence 24.1 (2018): 85-98.

Bishop, Sophie. "Managing visibility on YouTube through algorithmic gossip." new media \& society 21.11-12 (2019): 2589-2606.

Bishop, Sophie. "Anxiety, panic and self-optimization: Inequalities and the YouTube algorithm." Convergence 24.1 (2018): 69-84.

Burgess, Jean, and Joshua Green. YouTube: Online video and participatory culture. John Wiley \& Sons, 2018.

Burgess, Jean, and Ariadna Matamoros-Fernández. "Mapping sociocultural controversies across digital media platforms: One week of\# gamergate on Twitter, YouTube, and Tumblr." Communication Research and Practice 2.1 (2016): 79-96.

Cross, Katherine. "The Oscar Wilde Of Youtube Fights The Alt-Right With Decadence And Seduction." The Verge. N.p., 2018. Web. 29 Feb. 2020.

Cunningham, Stuart, David Craig, and Jon Silver. "YouTube, multichannel networks and the accelerated evolution of the new screen ecology." Convergence 22.4 (2016): 376391. 
Helmond, Anne. "The platformization of the web: Making web data platform ready." Social Media+ Society 1.2 (2015): 2056305115603080.

Lewis, Rebecca. 2019. “'This Is What the News Won't Show You': YouTube Creators and the Reactionary Politics of Micro-Celebrity." Television \& New Media, October, 1527476419879919.

Nieborg, David B., and Thomas Poell. "The platformization of cultural production: Theorizing the contingent cultural commodity." New Media \& Society 20.11 (2018): 4275-4292.

Norman, Chelsey. "The Alt-Right Arc: identity construction and audience uptake on YouTube." 2020 conference of the American Association for Applied Linguistics (AAAL). AAAL, 2020.

Postigo, Hector. "The socio-technical architecture of digital labor: Converting play into YouTube money." New media \& society 18.2 (2016): 332-349.

Rieder, Bernhard, and Guillaume Sire. "Conflicts of interest and incentives to bias: A microeconomic critique of Google's tangled position on the Web." New media \& society 16.2 (2014): 195-211.

Snickars, Pelle, and Patrick Vonderau. The youtube reader. Kungliga biblioteket, 2009.

Thrift, Nigel. Non-representational theory: Space, politics, affect. Routledge, 2008.

Tufekci, Zeynep. "Opinion | Youtube, The Great Radicalizer." Nytimes.com. N.p., 2018. Web. 29 Feb. 2020.

Tuters, Marc. 2020. "On the Problem of Reactionary Nonsense at the Bottom of the Web." EuropeNow, January. Accessed February 28, 2020. $<$ https://www.europenowjournal.org/2020/01/15/on-the-problem-of-reactionarynonsense-at-the-bottom-of-the-web/>. 
Van Es, Karin. 2020. "YouTube's Operational Logic: 'The View' as Pervasive Category." Television \& New Media 21 (3): 223-39.

Wynn, Natalie. Opulence | Contrapoints. YouTube: N.p., 2020. Video.

https://www.youtube.com/watch?v=jD-PbF3ywGo 